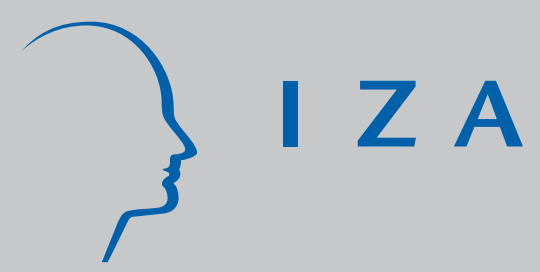

IZA DP No. 1058

Equilibrium Unemployment and Investment Under Product and Labour Market Imperfections

Heikki Kauppi

Erkki Koskela

Rune Stenbacka

March 2004 


\title{
Equilibrium Unemployment and Investment Under Product and Labour Market Imperfections
}

\author{
Heikki Kauppi \\ University of Helsinki \\ Erkki Koskela \\ University of Helsinki and IZA Bonn \\ Rune Stenbacka \\ Swedish School of Economics
}

Discussion Paper No. 1058

March 2004

\author{
IZA \\ P.O. Box 7240 \\ 53072 Bonn \\ Germany \\ Phone: +49-228-3894-0 \\ Fax: +49-228-3894-180 \\ Email: iza@iza.org
}

\begin{abstract}
Any opinions expressed here are those of the author(s) and not those of the institute. Research disseminated by IZA may include views on policy, but the institute itself takes no institutional policy positions.

The Institute for the Study of Labor (IZA) in Bonn is a local and virtual international research center and a place of communication between science, politics and business. IZA is an independent nonprofit company supported by Deutsche Post World Net. The center is associated with the University of Bonn and offers a stimulating research environment through its research networks, research support, and visitors and doctoral programs. IZA engages in (i) original and internationally competitive research in all fields of labor economics, (ii) development of policy concepts, and (iii) dissemination of research results and concepts to the interested public.
\end{abstract}

IZA Discussion Papers often represent preliminary work and are circulated to encourage discussion. Citation of such a paper should account for its provisional character. A revised version may be available on the IZA website (www.iza.org) or directly from the author. 


\section{ABSTRACT \\ Equilibrium Unemployment and Investment Under Product and Labour Market Imperfections*}

We study the implications of product market competition and investment for price setting, wage bargaining and thereby for equilibrium unemployment in an economy with product and labour market imperfections. We show that intensified product market competition will reduce equilibrium unemployment, whereas the effect of increased capital intensity is more complex. Higher capital intensity will decrease the equilibrium unemployment when the elasticity of substitution between capital and labour is less than one, while the reverse happens when this elasticity is higher than one but smaller than the elasticity of substitution between products. Finally, we demonstrate how labour and product market imperfections, characterized by the wage and price setting mark-ups, affect the optimal capital stock. Our findings raise important questions for future empirical research.

JEL Classification: E22, E24, J51, L11

Keywords: equilibrium unemployment, product market imperfections, investment, wage bargaining

Corresponding author:

Erkki Koskela

Department of Economics

University of Helsinki

P.O. Box 17 (Arkadiankatu 7)

00014 Helsinki

Finland

Email: erkki.koskela@helsinki.fi

\footnotetext{
* The authors thank the Research Unit on Economic Structures and Growth (RUESG) (University of Helsinki) as well as the Yrjö Jahnsson Foundation for financial support. Koskela also thanks Bank of Finland for hospitality.
} 


\section{Introduction}

We analyze the interaction between labour and product market imperfections as well as the role of investment behaviour - affected by capital markets - from the point of view of equilibrium unemployment. Our study fulfils a twofold purpose. Firstly, we explore the impact of long-term investments on wage formation, and thereby on unemployment, in an economy characterized by labour and product market imperfections. Secondly, we investigate the consequences of imperfections in the product market on equilibrium unemployment. In fact, we will design a theoretical model, which demonstrates that there are important interaction effects between labour market imperfections, product market imperfections and long-term investments and that these effects have implications for equilibrium unemployment. Finally, we explore how labour and product market imperfections affect the optimal capital stock.

The employment consequences of long-term investments have for a long time been a controversial issue in economics and this issue seems to underlie many disputes between firm owners and labour unions. In conventional models of imperfectly competitive labour markets - a la' Layard and Nickell and Jackmann (1991) - the investment behaviour has no effect on equilibrium unemployment. This is due to the specification of a Cobb-Douglas production function, which implies a constant wage elasticity of labour demand. Hence, investments or interest rate fluctuations will have no effect on the wage determination, achieved through wage negotiations due to the constant wage elasticity, and therefore no effect on equilibrium unemployment.

Many reservations can be raised against the Cobb-Douglas specification. The Cobb-Douglas specification does not seem to lie in conformity with empirics (see e.g. Lucas (1969), Rowthorn (1995), (1999) and Duffy and Papageorgiou (2000)). Furthermore, it has also been argued that when trying to explain variations in the labour share there is a need to depart from the usual assumption of a Cobb-Douglas production function (see Bentolila and Saint-Paul (2002)). Moreover, and related, medium- to long-term changes in unemployment appear to be correlated with medium- to long-term changes in private investment - a feature which does not seem to be consistent with predictions generated by models with Cobb-Douglas production 
functions (see Blanchard (1997) and, for some empirics, e.g. Herbertsson and Zoega (2002)). On the theoretical side Phelps (1994) has argued, applying an intertemporal customer market model, that higher real interest rates will raise the mark-ups in the product markets, leading to higher equilibrium unemployment. In the present paper we abandon the Cobb-Douglas specification and introduce a link between the longterm investment decisions and the negotiated wages by focusing on a more general class of CES production functions.

The employment consequences of intensified competition and deregulation in product markets have been analyzed to some extent in the recent literature. However, in this literature the potential role of investments has been abstracted away by postulating a production function with labour as the only production factor either in a linear (see Blanchard and Giavazzi (2003), Ebell and Haefke (2003)) or CobbDouglas form (see Spector (2004)). In what follows we extend the approach applied in these models by focusing on a general class of CES production functions within a framework where we capture the imperfections in product markets through monopolistic competition and those of the labour markets through a 'right-tomanage' union bargaining model. In particular, we incorporate the general CES-type production function with capital and labour inputs in such a way that the elasticity of substitution between the production factors will depend on the capital-labour ratio. ${ }^{1}$

In the present analysis we show that while intensified product market competition will decrease equilibrium unemployment, the effect of capital intensity is more complex. Higher capital intensity will moderate the negotiated wage rate and thereby reduce equilibrium unemployment when the elasticity of substitution between capital and labour is less than one. However, a higher capital intensity will have reverse effects when the elasticity of substitution is higher than one but smaller than the price elasticity of demand in the product market. Our analysis further verifies that the relationship between the capital stock and equilibrium unemployment would vanish in the special case of the Cobb-Douglas production function. Finally, we explore the determination of the optimal capital stock in the

\footnotetext{
${ }^{1}$ Hoon (1998) has developed a model with a different focus to study the interactions of unemployment and economic growth by assuming that the elasticity of substitution between capital and labour is less than one under the efficiency wage hypothesis.
} 
presence of product and labour market imperfections. Our new theoretical findings provide an important topic for empirical research.

We proceed as follows. Section II presents the basic structure of the model as well as the time sequence of decisions. Price setting and labour demand by firms are studied in section III. In section IV we analyze the wage determination through Nash bargaining. Section V explores the determinants of equilibrium unemployment. In section VI we investigate investment decisions under labour and product market imperfections. Finally, in section VII we present concluding comments.

\section{Basic Framework}

We focus on a model with product and labour market imperfections. In the long run, at stage 1, firms commit themselves to their investment programs, which determine the capital stocks. The investment decisions are made in anticipation of their effects on wage setting, price setting and labour demand. At stage 2 there is wage negotiation between firms and labour unions and at this stage the firms are committed to their investments. ${ }^{2}$ The wage negotiations take place in anticipation of the consequences for labour demand and price setting. Finally, at stage 3 firms make employment decisions and set prices by taking the negotiated wage rate and investment decision as given.

We summarize the time sequence of decisions in Figure 1. In the subsequent sections we derive the decisions taking place at different stages by using backward induction.
Stage 1
Stage 2
Stage 3

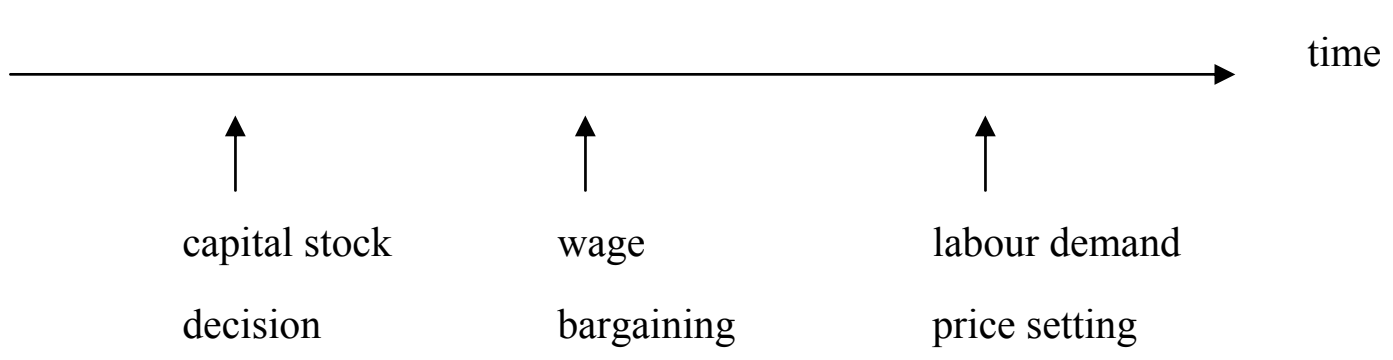

Figure 1: Time sequence of decisions

\footnotetext{
${ }^{2}$ This timing structure captures the idea of long-term investment decisions, which are inflexible at the stage when the wage negotiations are undertaken. Such a timing structure seems plausible when the investments represent, for example, irreversible technology choices.
} 
We postulate (for each firm $i$ ) a CES production function of the type

$$
R_{i}\left(K_{i}, L_{i}\right)=\left[(1-a) K_{i}^{\frac{\sigma-1}{\sigma}}+a L_{i}^{\frac{\sigma-1}{\sigma}}\right]^{\frac{\sigma}{\sigma-1}}, \quad i=1, \ldots, n
$$

where $K_{i}$ denotes firm $i$ 's capital stock, $L_{i}$ is the amount of labour, and $a$ and $\sigma$ are parameters satisfying $0<a<1$ and $\sigma>0$, respectively. The parameter $a$ is often called the distribution parameter (see e.g. Arrow at al (1961)), while $\sigma$ captures the elasticity of substitution between capital and labour. As we will see, this production function opens up a rich and interesting relationship between the capital stock and equilibrium unemployment. For reasons of comparison we also repeatedly consider the conventional case of Cobb-Douglas production function

$$
R_{i}\left(K_{i}, L_{i}\right)=K_{i}^{1-a} L_{i}^{a}, \quad i=1, \ldots, n
$$

where the elasticity of substitution between capital and labour is equal to one. Notice that in (1b) the parameter $a$ defines the labour share of production.

\section{Price Setting and Labour Demand}

The product market is modelled to operate with monopolistic competition a la' Dixit and Stiglitz (1977) and the firms face consumers endowed with the following CESutility function

$$
U=\left[n^{-\frac{1}{s}} \sum_{i=1}^{n} D_{i}^{\frac{s-1}{s}}\right]^{\frac{s}{s-1}}
$$

where $s$ denotes the elasticity of substitution between products. This elasticity could be thought of as an increasing function of the number of products offered according to $s=\bar{s} g(n)>1$, where $g^{\prime}(n)>0, \bar{s}$ is a constant and $n$ is the number of products (and firms). In the short run the number of firms is fixed so that $s$ is given, while in the long run there is free entry of new firms so that $s$ is determined endogenously (see e.g. Blanchard and Giavazzi (2003)). We take this elasticity of substitution (and thereby the number of products offered) as the measure of the degree of product market competition. A higher elasticity of substitution means a higher degree of product market competition and the limiting case of perfect competition is associated 
with the elasticity of substitution $s$ tending to infinity. The utility function in (2) has the special feature that an increase in the number of products does not increase utility directly. Technically, this due to the presence of $n^{-\frac{1}{s}}$ in the square brackets in (2). However, the increase of the number of products increases the elasticity of substitution between products, and thus the elasticity of demand facing firms (for more discussion and motivation see Blanchard and Giavazzi (2003, p. 882)).

A firm $i$ decides on price and employment so as to maximize the following profit function

$$
\underbrace{\max }_{p_{i}, L_{i}} \pi_{i}=p_{i} R_{i}\left(K_{i}, L_{i}\right)-w_{i} L_{i}
$$

At this stage the firm takes the negotiated wage rate $w_{i}$ and the capital stock $K_{i}$ as given. From the underlying utility functions of the consumers, given by (2), the demand in the product market can be seen to be of the form

$$
D_{i}=\frac{M}{P}\left(\frac{p_{i}}{P}\right)^{-s}
$$

where $p_{i}$ is the price of good $i, P \equiv\left[\frac{1}{n} \sum_{i=1}^{n} p_{i}^{1-s}\right]^{\frac{1}{1-s}}$ is the index of the aggregate price level, $M$ is the aggregate nominal income and $s>1$ is the elasticity of substitution between different products. Thus, $M / P$ denotes the real income. In Appendix A we derive the demand function (4) from the CES-utility function $(2)^{3}$. Furthermore, if we assume that the rents from capital are competed away in the long run, the aggregate nominal income is

$$
M=N[(1-u) w+u B]
$$

where $N$ denotes the number of individuals in the economy, $u$ is the unemployment rate, $w$ is the negotiated wage rate and $B$ is the unemployment compensation. It is important to point out that at this stage of the game the aggregate nominal income $M$ is exogenous, but later on both the wage rate $w$ and the unemployment rate $u$ are endogenized.

\footnotetext{
${ }^{3}$ See also Dixit and Stiglitz (1977).
} 
We can rewrite the CES production function (1a) as

$$
L_{i}=\left[\frac{1}{a} R_{i}^{\frac{\sigma-1}{\sigma}}-\frac{1-a}{a} K_{i}^{\frac{\sigma-1}{\sigma}}\right]^{\frac{\sigma}{\sigma-1}}
$$

By imposing market-clearing in the product markets, $D_{i}=R_{i}$, and by using (6) we can re-express the profit function (3) for the purpose of price setting according to

$$
\underbrace{\max }_{p_{i}} \pi_{i}=p_{i} D_{i}-w_{l} L_{i}=M\left(\frac{p_{i}}{P}\right)^{1-s}-w_{i}\left(\frac{1}{a}\left[\frac{M}{P}\left(\frac{p_{i}}{P}\right)^{-s}\right]^{\frac{\sigma-1}{\sigma}}-\frac{1-a}{a} K_{i}^{\frac{\sigma-1}{\sigma}}\right)^{\frac{\sigma}{\sigma-1}}
$$

where $M, P, K_{i}$ and $w_{i}$ are taken as given.

The necessary first-order condition associated with (7) can be expressed as

$$
(1-s)+w_{i}\left(\frac{1}{a}\left[\frac{M}{P}\left(\frac{p_{i}}{P}\right)^{-s}\right]^{\frac{\sigma-1}{\sigma}}-\frac{1-a}{a} K_{i}^{\frac{\sigma-1}{\sigma}}\right)^{\frac{1}{\sigma-1}} \frac{1}{a} \frac{s}{p_{i}}=0
$$

We can reformulate (8) according to the equation

$$
\left(\frac{(s-1) a}{s w_{i}}\right)^{\sigma-1} p_{i}^{\sigma-1}=\frac{1}{a}\left(\frac{M}{P}\left(\frac{p_{i}}{P}\right)^{-s}\right)^{\frac{\sigma-1}{\sigma}}-\frac{1-a}{a} K_{i}^{\frac{\sigma-1}{\sigma}}
$$

By imposing the symmetry condition $p_{i}=P$ for all $i$ (9) can be simplified according to the following price-setting rule

$$
\left.p_{i}\right|_{\sigma \neq 1}=\left(\left(M^{\frac{\sigma-1}{\sigma}}-(1-a) K_{i}^{\frac{\sigma-1}{\sigma}}\right)^{\frac{1}{\sigma-1}} w_{i} \mu(s) a^{-\frac{\sigma}{\sigma-1}}\right)^{\frac{\sigma}{\sigma+1}} \text { for all } i
$$

where $\mu(s)=\frac{s}{s-1}$, with $\mu^{\prime}(s)<0$, is the mark-up factor associated with the pricing equilibrium. This mark-up factor depends negatively on the elasticity of substitution between products. From equation (10a) and using the definition of the aggregate 
nominal income, $M$ in (5), we can attach the following qualitative properties to the price setting:

$$
\frac{\partial p_{i}}{\partial w_{i}}>0, \frac{\partial p_{i}}{\partial B}>0, \frac{\partial p_{i}}{\partial \mu}>0, \frac{\partial p_{i}}{\partial u}<0, \frac{\partial p_{i}}{\partial K_{i}}<0
$$

In the case of the Cobb-Douglas production function (1b) we can use a similar procedure to find the following price setting rule

$$
\left.p_{i}\right|_{\sigma=1}=a^{-a}\left(\frac{M_{i}}{K_{i}}\right)^{1-a}\left(w_{i} \mu(s)\right)^{a} \quad \text { for all } i
$$

As one can see the qualitative properties of $(10 b)$ are similar to those of (10a).

We can now summarize our characterization of the optimal price setting by firms in

Proposition 1 Higher wage rates, higher unemployment compensations or lower elasticities of substitution between products will all raise the equilibrium price in the product market, whereas higher unemployment rates or higher capital stocks will decrease it, ceteris paribus.

The pass-through effects - characterized in Proposition 1 - seem to appeal to intuition and several of these features are well known from the literature. An important new aspect in Proposition 1 is the role of the capital stock for the price setting. This aspect has been neglected in the earlier literature (see Blanchard and Giavazzi (2003), Ebell and Haefke (2003) and Spector (2004), where either linear or Cobb-Douglas production functions with labour being the only input were considered). An increase in the capital stock will increase production and thereby induce lower prices, ceteris paribus. This provides an alternative argument for the result by Phelps (1994) according to which lower interest rates will decrease the mark-up in the product markets.

In order to simplify notation we from now on mostly abstract from the firmspecific index associated with product $i$. Doing so the necessary first-order condition determining labour demand can be written as

$$
\pi_{L}=p R_{L}-w=0
$$


with the associated second-order condition $\pi_{L L}=p R_{L L}+p_{L} R_{L}<0$. Using the CES production function (1a) the first-order condition (12) can be expressed as

$$
\begin{gathered}
{\left[(1-a) K^{\frac{\sigma-1}{\sigma}}+a L^{\frac{\sigma-1}{\sigma}}\right]^{\frac{1}{\sigma-1}} a L^{-\frac{1}{\sigma}}=\frac{w}{p} \text { so that the labour demand is }} \\
\left.L\right|_{\sigma \neq 1}=K\left[\frac{1}{1-a}\left(\frac{w}{a p}\right)^{\sigma-1}-\frac{a}{1-a}\right]^{\frac{\sigma}{1-\sigma}}
\end{gathered}
$$

with $L_{K}>0$ and $L_{(w / p)}<0$. In the case of the Cobb-Douglas production function (1b) using a similar procedure we end up with the labour demand

$$
\left.L\right|_{\sigma=1}=K\left(\frac{w}{a p}\right)^{-\frac{1}{1-a}}
$$

with $L_{K}>0$ and $L_{(w / p)}<0$ as well. Notice that in the formulations of the labour demand functions in (13a) and (13b) the product price is endogenous as it implicitly depends on the wage rate.

The wage elasticity of labour demand, which turns out to be important later on, can be written in the case of the CES production function (1a) as (see Appendix B)

$$
\left.\eta(k, s)\right|_{\sigma \neq 1}=-\frac{L_{w} w}{L}=\frac{\sigma\left(1+\frac{1-a}{a} k^{\frac{\sigma-1}{\sigma}}\right)}{\frac{\sigma}{s}+\frac{1-a}{a} k^{\frac{\sigma-1}{\sigma}}}
$$

while the Cobb-Douglas production function leads to

$$
\left.\eta(s)\right|_{\sigma=1}=-\frac{L_{w} w}{L}=\frac{1}{1-a\left(\frac{s-1}{s}\right)},
$$

where $(s-1) / s=\mu(s)^{-1}$. From (14a) we can conclude that the wage elasticity of labour demand depends on the following four factors: the elasticity of substitution between capital and labour $(\sigma)$, the degree of competition in the product markets $(s)$, the capital-labour ratio $(k \equiv K / L)$ and the distribution parameter $a$. We 
observe that intensified product market competition, measured by higher elasticity of substitution between the products, increases the wage elasticity of labour demand, i.e. $\eta_{s}>0$. It is natural that more intense product market competition makes it harder for the firms to survive with higher wages and thus increased competition makes the firms' employment decisions more sensitive to changes in the wage rate. This feature holds true also in the case of Cobb-Douglas production function (see equation (14b)). ${ }^{4}$ When we approach a situation with perfect competition in the product markets (i.e., as $s \rightarrow \infty$ ) the wage elasticity of labour demand converges to $\sigma\left(1+\frac{a}{1-a} k^{\frac{1-\sigma}{\sigma}}\right)$, which reduces to $1 /(1-a)$ in the Cobb-Douglas case.

Next we ask, what is the effect of the capital-labour ratio $k$ on the wage elasticity of labour demand? This is an interesting question because, for example, the competitiveness of the capital markets and thereby the size of the capital stock will affect the capital intensity $k$. Differentiating (14a) with respect to $k$ yields

$$
\eta_{k}=\frac{\frac{1-a}{a}\left(\frac{(\sigma-1)(\sigma-s)}{s}\right) k^{-\frac{1}{\sigma}}}{\left[\frac{\sigma}{s}+\frac{1-a}{a} k^{\frac{\sigma-1}{\sigma}}\right]^{2}}
$$

where $s>1$. The comparative static effects of the capital intensity, $k$, on the wage elasticity of labour demand are illustrated in the $(\sigma, s)$-space in Figure 2. In this respect we can report the following findings: (i) Under gross complementarity between capital and labour $(\sigma<1)$ higher capital intensity increases the wage elasticity of labour demand. (ii) The same happens under gross substitutability $(\sigma>1)$ as long as the elasticity of substitution between products $(s)$ is lower than the elasticity of substitution between capital and labour in the production function. (iii) Under gross substitutability $(\sigma>1)$ the wage elasticity is a decreasing function

\footnotetext{
4 There is empirical evidence according to which product market regulation has decreased and thereby competition increased in OECD countries during the 1990s (for evidence, see Nicoletti, Bassanini, Ernst, Jean, Santiago and Swaim (2001)). Gersbach (2000) summarizes three mechanisms (lower markups, higher total factor productivity and expanded sets of product varieties), through which reductions in product market imperfections might enhance employment. Blanchard and Philippon (2003) design a "minimalist model" to explore the effects of intensified product market competition when labour unions learn slowly about structural changes in the economic environment and when trust plays an important role in the labour market.
} 
of the capital intensity if the elasticity of substitution between products $(s)$ is higher than the elasticity of substitution between capital and labour in the production function. We can explain these relationships by reference to the following interpretations: While under gross substitutability, ceteris paribus, a higher capital intensity reduces the wage elasticity of labour demand, a higher capital stock will decrease the price mark-up and therefore has the reverse effect on the wage elasticity. The latter effect dominates when $s>\sigma$ whereas the former effect dominates if $s<\sigma$. In this latter case a higher capital intensity will increase the wage elasticity of labour demand even though capital and labour are gross substitutes.

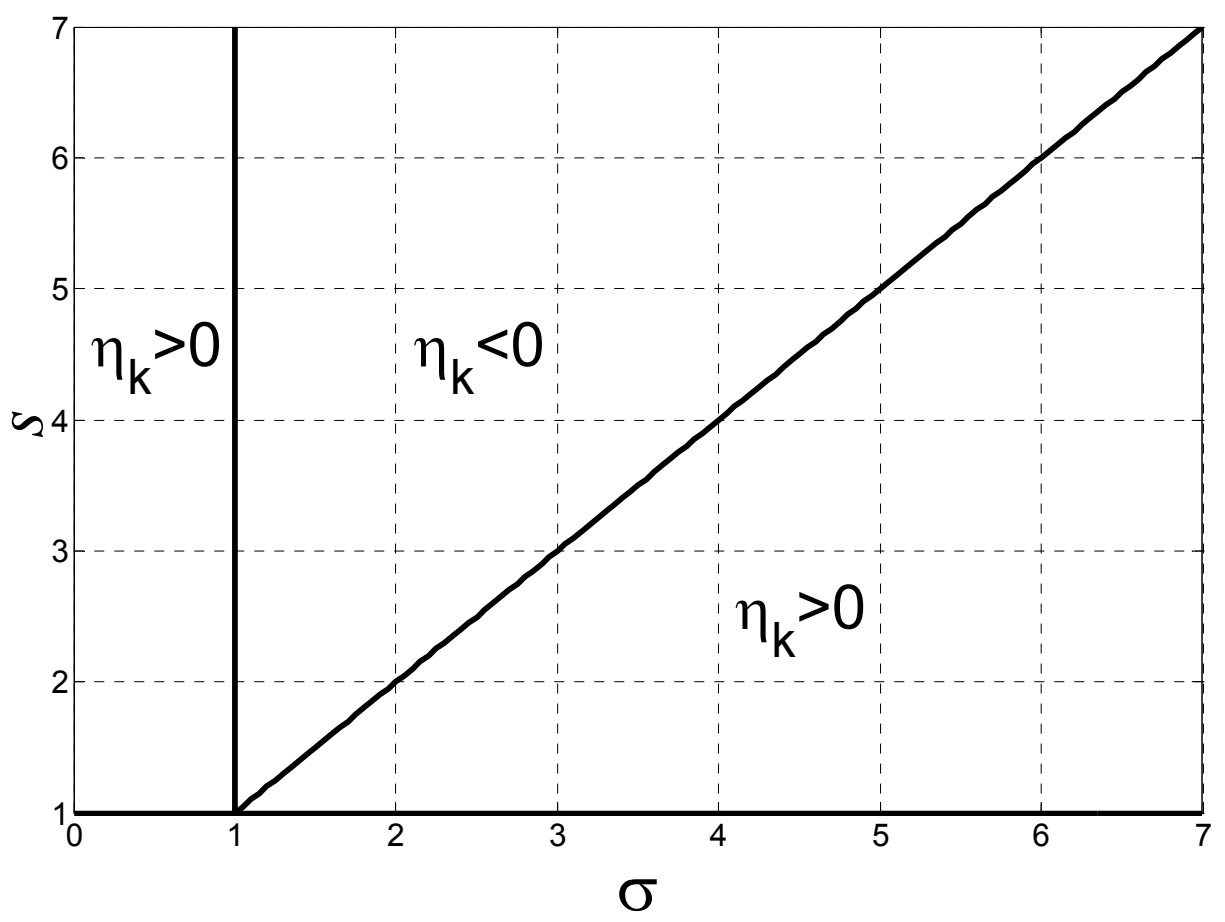

Figure 2: The effect of the capital-labour ratio on the wage elasticity of labour demand

We can summarize our findings in

Proposition 2 Intensified product market competition will always increase wage elasticity of labour demand. A higher capital intensity will increase the wage elasticity of labour demand when the elasticity of substitution between labour and capital is less than one or when it is higher than one but smaller than the elasticity of 
substitution between products. But, if the elasticity of substitution between the production factors is higher than the elasticity of substitution between the products, an increase in capital intensity will decrease the wage elasticity.

From Proposition 2 we can conclude that the technological elasticity of substitution between the production factors is of primary importance for the relationship between capital intensity and the wage elasticity of labour demand. Basically, the wage elasticity of labour demand is an increasing function of the capital intensity except for such a case of technological gross substitutability where an offsetting effect with reduced price mark-ups is sufficiently strong. Such an offsetting effect is sufficiently strong precisely when the degree of product market competition is high.

Finally, (14b) reveals the following result in the Cobb-Douglas case

Corollary 1: The wage elasticity of labour demand is independent of the capital intensity in the case of a Cobb-Douglas production function.

Corollary 1 verifies the conventional assumption, whereby there is no relationship between wage elasticity and investment under circumstances with CobbDouglas production functions. Thus, this type of production function eliminates the potential channel through which credit market behaviour might impact on wage elasticity via the determination of the capital stock.

\section{Wage Determination via Nash Bargaining}

We now turn to look at the stage of wage determination by taking the capital stock $K$ as given. We apply the Nash bargaining solution within the context of the 'rightto-manage' approach according to which employment is unilaterally determined by the firms. The wage bargaining takes place in anticipation of optimal price and employment decisions by the firms. Following the Nash bargaining approach the firm and the labour union negotiate with respect to the wage so as to solve the optimization problem

$$
\underbrace{\max }_{w} \Omega=\left[L^{*}(w-b)\right]^{\beta}\left[p R\left(K, L^{*}\right)-w L^{*}\right]^{1-\beta} \text { so that } \pi_{L}=0 \text { and } \pi_{p}=0
$$


where the relative bargaining power of the union is $\beta$ and that of the firm is $(1-\beta)$, $L^{*}(w-b)=E U, b$ is the (exogenous) outside option available to union members and $\pi=p R(K, L)-w L$. The outside options for the firm and the union are $\pi^{o}=-\Delta K$ and $U^{o}=M b$, respectively, where $M$ is the number of labour union members and $\Delta=1+r$ denotes the cost of capital. Under these assumptions the necessary first-order condition for the wage determination can be written as

$$
\beta \frac{U_{w}}{U}+(1-\beta) \frac{\pi_{w}}{\pi}=0
$$

where

$$
\frac{U_{w}}{U}=\frac{1}{w} \frac{[w(1-\eta(k, s))+b \eta(k, s)]}{w-b} .
$$

and

$$
\frac{\pi_{w}}{\pi}=-\frac{1}{w} \frac{w L^{*}}{\pi}=-\frac{1}{w} \frac{p R_{L} L^{*}}{\pi}=-\frac{1}{w} \frac{p R_{L} L^{*}}{p\left[R-R_{L} L^{*}\right]}=-\frac{1}{w} \frac{a}{1-a} k^{\frac{1-\sigma}{\sigma}} .
$$

Substituting the expressions (18a) and (18b) into the first-order condition (17) yields, after some rearrangement, the following Nash bargaining solutions for the wage rate in the case of CES (1a) and Cobb-Douglas (1b) production functions

$$
\left.w^{N}\right|_{\sigma \neq 1}=\left[1+\frac{\beta}{\beta(\eta(k, s)-1)+(1-\beta) \frac{a}{1-a} k^{\frac{1-\sigma}{\sigma}}}\right] b .
$$

and

$$
\left.w^{N}\right|_{\sigma=1}=\left[1+\frac{\beta}{\beta(\eta(s)-1)+(1-\beta) \frac{a}{1-a}}\right] b
$$

According to (19a) and (19b) the negotiated wage rate depends positively on the outside option $(b)$ and on the relative bargaining power of the labour union $(\beta)$, while negatively on wage elasticity of labour demand $(\eta)$. As we described in 
Proposition 2, the wage elasticity of labour demand depends positively on product market competition $(s)$. Further, the relationship between the wage elasticity of demand $(\eta)$ and the capital-labour ratio $(k)$ depends on the size of the elasticity of substitution $(\sigma)$ between capital and labour in the production function as well as on the relative sizes of $\sigma$ and $s$. In particular, as we approach perfect product market competition with $s \rightarrow \infty$ in the Cobb-Douglas case, the wage rate converges towards $[1+\beta(1-a) / a] b=[1+\beta /(\eta-1)] b$, where $\eta=1 /(1-a)$ is the wage elasticity of labour demand under perfect product market competition.

Differentiating the wage rate (19a) with respect to the capital-labour ratio gives

$$
\frac{\partial w^{N}}{\partial k}=\frac{-\beta\left[\beta \eta_{k}(k, s)+(1-\beta) \frac{1-\sigma}{\sigma} \frac{a}{1-a} k^{\frac{1-2 \sigma}{\sigma}}\right]}{\left[\beta(\eta(k, s)-1)+(1-\beta) \frac{a}{1-a} k^{\frac{1-\sigma}{\sigma}}\right]^{2}}\left\{\begin{array}{l}
<0 \\
=0 \\
>0 \\
?
\end{array}\right\} \text { as }\left\{\begin{array}{l}
\sigma<1 \\
\sigma=1 \\
1<\sigma<s \\
1<s<\sigma
\end{array}\right\}
$$

Expression (20) characterizes the capital stock as a strategic commitment device. We can delineate the outcome (20) as follows: First, under gross complementarity between capital and labour $(\sigma<1)$ higher capital intensity decreases the negotiated wage rate via two channels: (1) it becomes harder for the union to extract rent in negotiations because of higher wage elasticity of labour demand, and (2) a higher capital-labor ratio increases the negative effect of the wage rate on the profit, i.e. $\frac{\partial}{\partial k}\left(\frac{\pi_{w}}{\pi}\right)<0$ when $(\sigma<1)$ and thus moderates wage formation. Second, the reverse happens under gross substitutability $(\sigma>1)$ if the elasticity of substitution is smaller than the price elasticity of product demand. The interpretation of this finding is analogous to the former case. Finally, if under gross substitutability $(\sigma>1)$ the price elasticity of product demand is smaller than the elasticity of substitution, the effect of capital intensity on wage determination is a priori ambiguous and it depends on the relative bargaining power of labour union, the level of capital intensity, the degree of product market competition, and the value of the distribution parameter. In particular, one can see from (20) that in the case $1<s<\sigma$ we have 


$$
\frac{\partial w^{N}}{\partial k}\left\{\begin{array}{l}
> \\
= \\
<
\end{array}\right\} \quad \text { as } \beta\left\{\begin{array}{l}
< \\
= \\
>
\end{array}\right\} \frac{1}{\eta_{k}} \frac{\sigma-1}{\sigma} \frac{a}{1-a} k^{\frac{1-2 \sigma}{\sigma}} .
$$

Figure 3 illustrates the effect of the capital intensity on the negotiated wage in the $(\sigma, s)$ - space for different values of the relative bargaining power of the labour union. We observe that an increased capital intensity induces wage moderation for combinations with sufficiently high elasticity of substitution between capital and labour and a sufficiently low degree of competition in the product market, measured by the elasticity of substitution between products. On the other hand, a sufficiently strong intensification of competition in the product market will change this relationship. Hence, with a reasonably moderate elasticity of substitution between the production factors sufficiently intense product market competition will lead to a relationship whereby the negotiated wage rate increases as a function of the capital intensity. From Figure 3 we can also infer that the region characterized by wage moderation is increasing as a function of the bargaining power of the labour union. This means that the capital intensity provides a stronger strategic commitment device for the generation of wage moderation the larger is the labour market imperfections characterized by the bargaining power of the labour unions. ${ }^{5}$ Figure 4 illustrates how the distribution parameter $a$ impacts on the relationship between wage formation and capital intensity.

We now summarize our analysis of wage bargaining in

Proposition 3 The negotiated wage rate depends negatively on the wage elasticity of labour demand and therefore intensified product market competition will decrease the wage rate. Higher capital intensity will decrease the negotiated wage rate if the elasticity of substitution between capital and labour is smaller than one while the reverse happens if it is higher than one, but smaller than the price elasticity of product demand. But if the elasticity of substitution between the production factors exceeds both one and the price elasticity of substitution between products, the impact of capital intensity is a priori ambiguous.

\footnotetext{
${ }^{5}$ This feature reminds of the wage-moderating effect of profit sharing on the negotiated base wage. As Koskela and Stenbacka (2003) demonstrate, the wage-moderating effect of profit sharing is stronger the larger are the imperfections in the labour market.
} 


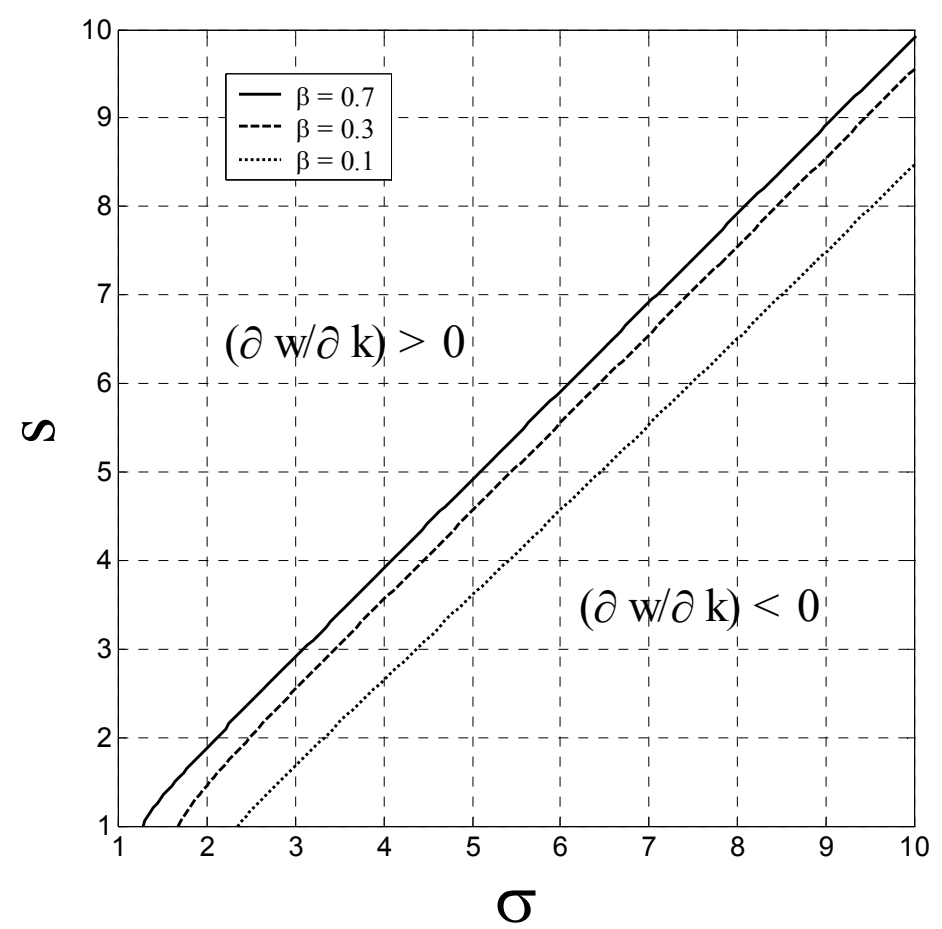

Figure 3: The effect of the capital-labor ratio on the wage rate with different values of the labour union's bargaining power

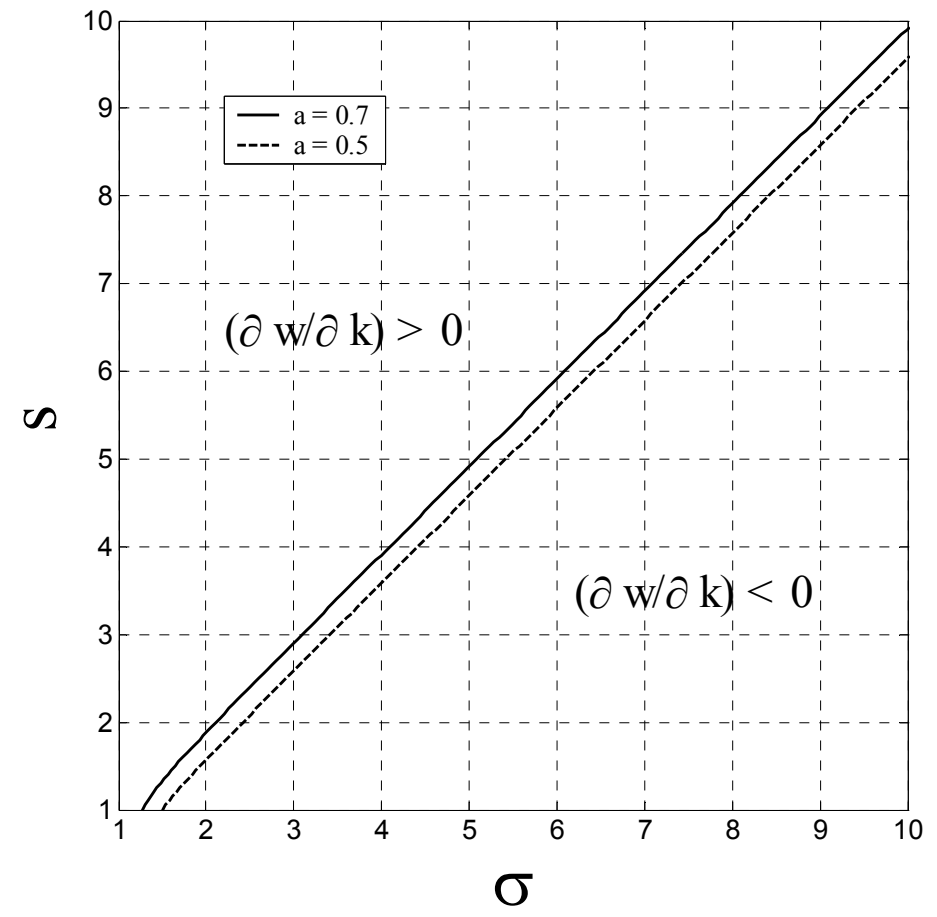

Figure 4: The effect of the capital-labor ratio on the wage rate with different distribution parameter values 
Finally, if the production function is Cobb-Douglas we can replicate the Layard, Nickell and Jackman (1991) finding according to which the capital stock does not affect wage formation. ${ }^{6}$

Corollary 2 With a Cobb-Douglas production function capital intensity will have no effect on the negotiated wage.

From the negotiated Nash wage we get interesting special cases. If all the bargaining power lies with the union $(\beta=1)$, the Nash bargaining solution is simplified to the monopoly union solution

$$
\left.w^{M}\right|_{\sigma \neq 1}=\frac{\eta(k, s)}{\eta(k, s)-1} b \text { and }\left.w^{M}\right|_{\sigma=1}=\frac{\eta(s)}{\eta(s)-1} b
$$

according to which the wage mark-up depends negatively on the wage elasticity of labour demand which is a function of the capital-labour ratio $k$ when $\sigma \neq 1$ while it is not when $\sigma=1$. Further the wage elasticity of labour demand is an increasing function of the price elasticity of product demand $s$.

If all the bargaining power lies with the firm $(\beta=0)$, the relationship between the negotiated wage and the capital intensity disappears. In this case the negotiated wage converges to the competitive wage with $w^{C}=b$, i.e. the wage mark-up is eroded. Intuitively this seems to make sense for the following reason. The capital intensity serves as a strategic commitment device, which will affect the distribution of the rents achieved through bargaining, in imperfectly competitive labour markets. ${ }^{7}$ Once the labour market imperfections are eroded the capital intensity can no longer play such a strategic role.

There is empirical evidence according to which higher product market competition will moderate wage formation. See e.g. Abowd and Lemieux (1993) using Canadian data, Nickell and Vainiomaki and Wadhwani (1994) using data from

\footnotetext{
${ }^{6}$ It is interesting to observe that wages are assumed to always depend positively on the capital intensity in Denny and Nickell (1992). As (20) makes clear this is far from self-evident.

${ }^{7}$ In other contexts both the capital structure and the compensation scheme have been shown to constitute a similar type of commitment device (see e.g. Dasgupta and Sengupta (1993) and Koskela and Stenbacka (2004)).
} 
British manufacturing companies and Neven and Röller and Zhang (1999), who have used the data from eight European airline companies to analyze links between product market competition and union power. Nickell (1999) presents a survey of this literature.

\section{Product Markets, Capital Intensity and Equilibrium Unemployment}

Above we have characterized wage formation, labour demand and price setting from a partial equilibrium perspective. We now move on to explore the determinants of equilibrium unemployment in a general equilibrium framework. We are particularly interested in the relationships between capital stock, and thereby the capital intensity, the intensity of competition in the product market and the equilibrium unemployment.

According to (19a) and (19b) the negotiated wage rate in industry $i$ is of the form $w_{i}^{N}=A_{i} b$, where the mark-up factors in the cases of CES- and Cobb-Douglas production functions

$$
\left.A\right|_{\sigma \neq 1}=1+\frac{\beta}{\beta(\eta(k, s)-1)+(1-\beta) \frac{a}{1-a} k^{\frac{1-\sigma}{\sigma}}}
$$

and

$$
\left.A\right|_{\sigma=1}=1+\frac{\beta}{\beta(\eta(s)-1)+(1-\beta) \frac{a}{1-a}}
$$

are, in principle, industry-specific. We impose symmetry assumptions meaning that $A_{i}=A$ and $w_{i}^{N}=w^{N}$ for all $i$. In a general equilibrium the term $b$ should be reinterpreted as the relevant outside option, which we specify as

$$
b=(1-u) w^{N}+u B
$$

where $u$ is the unemployment rate, $B$ captures the unemployment benefit and $w^{N}$ denotes the negotiated wage rate in all identical industries. Assuming a constant 
benefit replacement ratio $q=B / w^{N}$ and substituting (23) for $b$ into the Nash bargaining solutions (19a) and (19b) yields the equilibrium unemployment

$$
u^{N}=\frac{1}{1-q}\left[1-\frac{1}{A}\right]
$$

where the wage mark-up $A$ is given by (21a) for $\sigma \neq 1$ and by (21b) for $\sigma=1$.

According to (24) a higher benefit-replacement ratio, $q$, and a higher mark-up in the wage determination, $A$, will increase equilibrium unemployment. Further, from the mark-ups in the wage determination we can conclude that higher wage elasticity of labour demand will decrease equilibrium unemployment. In fact, differentiating (22a) with respect to $s$ gives

$$
A_{s}=-\frac{\beta^{2} \eta_{s}}{\left[\beta(\eta(k, s)-1)+(1-\beta) \frac{a}{1-a} k^{\frac{1-\sigma}{\sigma}}\right]^{2}}<0
$$

meaning that intensified product market competition will moderate the wage markup in the general case $\sigma \neq 1$. The same qualitative result holds true also in the case with $\sigma=1$ as can be seen by differentiating (22b) with respect to $s$. Hence, intensified product market competition will, ceteris paribus, decrease equilibrium unemployment because $\eta_{s}>0$ and $\frac{\partial u^{N}}{\partial \eta}<0$.

As for the impact of the capital-labour ratio on equilibrium unemployment we initially observe that

$$
A_{k}=-\frac{\beta\left[\beta \eta_{k}+(1-\beta) \frac{1-\sigma}{\sigma} \frac{a}{1-a} k^{\frac{1-2 \sigma}{\sigma}}\right]}{\left[\beta(\eta(k, s)-1)+(1-\beta) \frac{a}{1-a} k^{\frac{1-\sigma}{\sigma}}\right]^{2}}\left\{\begin{array}{l}
<0 \\
=0 \\
>0 \\
?
\end{array}\right\} \text { as }\left\{\begin{array}{l}
\sigma<1 \\
\sigma=1 \\
1<\sigma<s \\
1<s<\sigma
\end{array}\right\}
$$

(26) offers a characterization of the capital stock as a strategic commitment device with employment effects. Because it holds true that $\frac{\partial w_{k}^{N}}{\partial k}=A_{k} b$, we can explore the effect of the capital intensity on equilibrium unemployment by combining (20) and 
(26). The relationship between the negotiated wage and the capital intensity was characterized in Proposition 3. According to Proposition 3 more intense product market competition will, ceteris paribus, moderate the negotiated wages and thereby decrease equilibrium unemployment, while the relationship between capital intensity, wage formation and thereby the relationship between capital intensity and equilibrium unemployment is more complicated. More specifically, it depends on the size of the elasticity of substitution between production factors, on the degree of product market competition, measured by the price elasticity of demand as well as on the relative sizes of these two parameters.

Our findings concerning the determinants of equilibrium unemployment can now be summarized in

Proposition 4 Increased product market competition will reduce equilibrium unemployment. Higher capital intensity will reduce equilibrium unemployment when the elasticity of substitution between capital and labour is smaller than one while the reverse happens when it is higher than one, but smaller than the price elasticity of product demand. But if the elasticity of substitution lies between one and the elasticity of substitution between the production factors (larger than one), then the effect of capital intensity on equilibrium unemployment is a priori ambiguous.

According to Proposition 4 the effect of capital intensity - and thereby also the effect of the interest rate and thereby possibly the effect of the degree of credit market competition - on equilibrium unemployment depends both on the size of the elasticity of substitution between labour and capital and on the relationship between it and product market competition, measured by the price elasticity of product demand. Rowthorn (1999) has argued that the elasticity of substitution is smaller than one. Duffy and Papageorgiou (2000) have used a panel of 82 countries over a 28-year period to estimate a general CES production function specification. For the entire sample they reject the Cobb-Douglas specification, but for the richest group of countries $\sigma$ is higher than one and for the poorest group of countries lower than one.

Finally, for the special case with a Cobb-Douglas production function we again reproduce the Layard, Nickell and Jackman (1991) finding according to which capital stock does not affect wage formation. 
Corollary 3 With a Cobb-Douglas production function equilibrium unemployment is independent of the capital intensity.

Our results regarding the relationship between labour market imperfections, product market imperfections, investments and equilibrium unemployment are related to a few recent research contributions. Blanchard and Giavazzi (2003) and Spector (2004) have earlier theoretically studied the employment consequences of product market competition and deregulation within a bargaining framework. Ebell and Haefke (2003) apply a dynamic matching model to explore the dynamic relationship between product market competition and equilibrium unemployment. In contrast to Blanchard and Giavazzi (2003) and Spector (2004), Ebell and Haefke (2003) make use of a Cournot model where the number of firms competing in each industry measures the intensity of product market competition. All these contributions, however, abstract from the determination of capital stock and, in particular, from its potential implications for employment by assuming either the linear or Cobb-Douglas production function with labour being the only production factor. As our study makes clear, the characterization of equilibrium unemployment is bound to be incomplete under such restrictions to the models. As we have shown, the interactions between labour market imperfections, product market imperfections and the capital intensity have important implications for the wage formation, and thereby for equilibrium unemployment.

\section{Investment Decisions under Labour and Product Market Imperfections}

As the final part of our study we turn to briefly explore the initial stage of the decision-making structure, i.e. the decision whereby firms determine their capital stock. The capital stock is determined in the presence of rational expectations regarding the outcomes of the wage negotiation, the employment decisions and the price setting by firms. Hence, in the long run firms enter the industry with a capital stock, which is set to solve the following optimization problem

$$
\begin{aligned}
& \underbrace{\max }_{K_{i}} \pi=p_{i} R\left(K_{i}, L_{i}^{*}\right)-w_{i} L_{i}^{*}-(\Delta+c) K_{i}, \text { for all } i \\
& \text { s.t. } \quad \Omega_{w}=0, \pi_{L_{i}}^{i}=0 \text { and } \pi_{p_{i}}^{i}=0,
\end{aligned}
$$


where $\Delta=1+r$ denotes the cost of capital. The parameter $c$ captures the cost of entering the industry in question. We assume, following Alesina et al (2003), that this entry cost is proportional to the capital stock $K{ }^{8}$ As these authors emphasize this entry cost could capture the effects of regulation on entry. Using the envelope theorem, according to which both $\pi_{L_{i}}=0$ and $\pi_{p_{i}}=0$, the first-order condition for the capital stock can be written in the cases of CES- and Cobb-Douglas production functions according to

$$
\left.\frac{\partial \pi_{i}}{\partial K_{i}}\right|_{\sigma \neq 1}=p_{i} \frac{\partial R_{i}}{\partial K_{i}}-\frac{\partial w_{i}^{N}}{\partial K_{i}} L_{i}^{*}-(\Delta+c)=0
$$

and

$$
\left.\frac{\partial \pi_{i}}{\partial K_{i}}\right|_{\sigma=1}=p_{i} \frac{\partial R_{i}}{\partial K_{i}}-(\Delta+c)=0
$$

In general, the capital stock depends on the size of the elasticity of substitution between capital and labour.

We can rewrite equation (28a) according to

$$
\left.\frac{\partial R_{i}}{\partial K_{i}}\right|_{\sigma \neq 1}=\frac{\Delta+c+\frac{\partial w_{i}^{N}}{\partial K_{i}} L_{i}^{*}}{p_{i}}
$$

Expression (29) defines the optimal capital stock as an implicit function of the product and labour market imperfections. We can attach the following interpretation to equation (29). Lower costs of capital, i.e. more competitive capital markets, and lower entry costs, i.e. deregulation of entry barriers and entry-promoting competition policies, will decrease the total cost, defined by the RHS of (29), so that the privately optimal capital stock will increase. Furthermore, a higher elasticity of substitution between products, defined by $s$, will decrease $p_{i}$, which will have a negative direct effect on the capital stock. This holds true because intensified product market competition will reduce the marginal product of investment, ceteris paribus. In

\footnotetext{
${ }^{8}$ In their model restricted to labour as the only production factor also Blanchard and Giavazzi (2003) endogenize product market competition by making use of an entry cost which is proportional to output.
} 
addition, this elasticity of demand substitution, $s$, will also affect the capital stock via the term $\frac{\partial w_{i}^{N}}{\partial K_{i}}$ in a way which depends on the relationship between $\sigma$ and $s$ as characterized by Proposition 3. Hence, the impact of labour market imperfections, characterized by the wage setting mark-up, on the capital stock determination depends both on the degree of imperfections in the product markets and the elasticity of substitution between capital and labour.

Denny and Nickell (1992) have empirically studied the relationship between investments and unions in British industries. According to their findings the rate of investment is about $30 \%$ lower in firms which recognize unions relative to those in which unions are not recognized. Alesina et al (2003) have used OECD data to study how various measures of regulation in the product market, concerning in particular entry barriers, are related to investment behaviour. According to their findings product market deregulation seems to have a statistically significant negative effect on investment behaviour, ceteris paribus. It should however be emphasized that the analysis of Alesina et al abstracts from labour market frictions.

As a special case we can investigate the optimal capital stock in the absence of product market imperfections, i.e. in the limiting case with $s \rightarrow \infty$. Here both the price elasticity of product demand $s$ and entry costs $c$ have been postulated independently. But it is plausible that the entry cost will affect the number of firms and products negatively and thereby the price elasticity of products as well, i.e. $n=n(c)$ with $n^{\prime}(c)<0$ and $s=s(n)$ with $s^{\prime}(n)>0$ so that $s^{\prime}(c)<0$.

In the case of Cobb-Douglas production function (1b) with the price setting equation (10b) we can rewrite the first-order condition for the capital stock (28b) as

$$
a^{-a}\left(\frac{M_{i}}{K_{i}}\right)^{1-a}\left(w_{i} \mu(s)\right)^{a}(1-a) K_{i}^{-a} L_{i}^{a}=\Delta+c
$$

This can be explicitly solved to yield

$$
\left.K_{i}^{*}\right|_{\sigma=1}=\frac{(1-a)}{(\Delta+c)}\left[a^{-a}\left(w_{i}^{N} \mu(s)\right)^{a} M^{1-a} L_{i}^{a}\right]
$$


According to (30) $\frac{\partial K_{i}^{*}}{\partial \Delta}, \frac{\partial K_{i}^{*}}{\partial c}<0$ and $\frac{\partial K_{i}^{*}}{\partial \mu}, \frac{\partial K_{i}^{*}}{\partial M}>0$ meaning that a higher interest rate factor and higher entry costs will decrease capital stock, while higher mark-ups due to less competitive product markets and higher aggregate nominal incomes will increase capital stock, ceteris paribus. If we assume that entry costs will affect the number of firms and products negatively and thereby the price elasticity of product as well, i.e. $n=n(c)$ with $n^{\prime}(c)<0$ and $s=s(n)$ with $s^{\prime}(n)>0$ so that $s^{\prime}(c)<0$, then intensified product market competition resulting from lower entry costs will have on ambiguous effect on investment behaviour. More precisely, the effect through the wage has a positive effect via price setting (see equation (10b)) and a negative effect via labour demand (see equation 13b)). The negative effect dominates so that a higher wage rate, due to higher outside option (b) or higher relative bargaining power $(\beta)$, will decrease the private optimal capital stock. This is because capital and labour are complements in the sense that their marginal products depend positively on the amount of the other input.

\section{Conclusions}

The employment consequences of intensified competition and deregulation in product markets have been analyzed to some extent in the recent literature. However, in this literature the potential role of investments has been abstracted away by postulating a production function with labour as the only production factor either in a linear (see Blanchard and Giavazzi (2003), Ebell and Haefke (2003)) or CobbDouglas form (see Spector (2004)). Our starting point has been similar to these studies in that we have assumed imperfect competition in the product and labour markets, but importantly we have generalized these models by assuming a more general and realistic CES-type production function, in which the elasticity of substitution between capital and labour can be different from one. This has established a new framework for studying the interaction effects between imperfections in labour and product markets and long-term investments for the determination of equilibrium unemployment. In particular, this has made it possible to explore the potential determinants of equilibrium unemployment in realistic environments with imperfections in both product and labour markets. 
We have shown the following new results. While a higher degree of product market competition, ceteris paribus, will decrease equilibrium unemployment, the effect of capital intensity is more complex. The capital intensity serves as a strategic commitment device with which the owners of the firms can affect the distribution of rents achieved through bargaining in imperfectly competitive labour markets. In fact, the negotiated wage rate decreases, and therefore also equilibrium unemployment declines, as a result of higher capital intensity when the elasticity of substitution between capital and labour is less than one, while the reverse happens when the elasticity of substitution is higher than one but smaller than the price elasticity of product demand. But if the elasticity of substitution is both higher than one and exceeds the price elasticity of product demand, the impact of capital intensity is a priori ambiguous. In this case the relative bargaining power of the labour unions turns out to play an important role in determining what combinations of the elasticity of substitution between production factors and the price elasticity of product demand make higher capital stock increase equilibrium unemployment. As a special case of Cobb-Douglas production function the relationship between capital stock and equilibrium unemployment will vanish.

Finally, when the negotiated wage converges to the competitive rate the capital intensity does no longer - even in the case of CES production function - serve as a strategic commitment device which would affect the distribution of the rents. Thus once the labour market imperfections are eroded the capital intensity can no longer play such a strategic role. Finally, we demonstrated how labour and product market imperfections, characterized by the wage and price setting mark-ups, affect the optimal capital stock. In particular, the optimal capital stock was seen to depend both on the degree of imperfections in the product markets and the elasticity of substitution between capital and labour. Our new theoretical findings raise interesting empirical questions for future research and stress the importance of obtaining reliable estimates for the elasticity of substitution between labour and capital inputs. 


\section{References:}

Abowd, J. A., Lemieux, T. (1993): The Effects of Product Market Competition on Collective Bargaining Agreements: the Case of Foreign Competition in Canada, Quarterly Journal of Economics, 108, 984-1014.

Alesina, A., Ardagna, S., Nicoletti, G., Schiantarelli, F. (2003): Regulation and Investment, NBER working paper, No. 9560, March.

Arrow, K. J., Chenery, H.B., Minhas, B. S., Solow, R. M. (1961): Capital-Labor Substitution and Economic Efficiency, Review of Economics and Statistics, XLIII, 225-250.

Bentolila, S., Saint-Paul, G. (2003): Explaining Movements in the Labor Share, Contributions to Macroeconomics, 3, 1-31.

Blanchard, O. (1997): The Medium Run, Brookings Papers on Economic Activity, 2, 89-158.

Blanchard, O., Giavazzi, F. (2003): Macroeconomic Effects of Regulation and Deregulation in Goods and Labor Markets, Quarterly Journal of Economics, $118,879-907$.

Blanchard, O., Philippon, T. (2003): The Decline of Rents, and the Rise and Fall of European Unemployment, Mimeo, February.

Dasgupta, S. , Sengupta, S. (1993): Sunk Investment, Bargaining, and Choice of Capital Structure, International Economic Review, 34, 203-220.

Denny, K., Nickell, S. J. (1992): Unions and Investments in British Industry, Economic Journal, 102, 874-887.

Dixit, A. K., Stiglitz, J. E. (1977): Monopolistic Competition and Optimum Product Diversity, American Economic Review, 67, 297-308.

Duffy, J., Papageorgiou, C. (2000): A Cross-Country Empirical Investigation of the Aggregate Production Function Specification, Journal of Economic Growth, 5, 87-129.

Ebell, M., Haefke, C. (2003): Product Market Deregulation and Labor Market Outcomes, working paper, Universitat Pompeu Fabra.

Gersbach, H. (2000): Promoting Product Market Competition to Reduce Unemployment in Alternative Approach?, Kyklos, 53(2), 117-134.

Herbertsson, T. T., Goega, G. (2002): The Modigliani 'Puzzle', Economics Letters, $76,437-442$.

Hoon, H. T. (1998): Capital Expansion, Endogenous Growth and Equilibrium unemployment, Australian Economic Papers, 257-272.

Koskela, E., Stenbacka, R. (2003): Profit Sharing and Unemployment: An Approach with Bargaining and Efficiency Wage Effects, Journal of Institutional and Theoretical Economics, forthcoming. 
Koskela, E., Stenbacka, R. (2004): Profit Sharing, Credit Market Imperfections and Equilibrium Unemployment, IZA Discussion Paper No. 1020.

Layard, R., Nickell, S.J., Jackman,R. (1991): Unemployment: Macroeconomic Performance and Labour Markets, Oxford University Press.

Lucas, R. (1969): Labor-Capital Substitution in US Manufacturing, in Harberger, A. and Bailey, M. (eds): The Taxation of Income from Capital, The Brookings Institution, Washington, pp. 223-274.

Neven, D.M., Röller, L-H., Zhang, Z. (1999): Union Power and Product Market Competitiion: Evidence from the Airline Industry, WZB working paper 99-05.

Nickell, S., Vainiomaki, J., Wadhwani, S. (1994): Wages and Product Market Power, Economica, 61, 457-473.

Nickell, S. (1999): Product Markets and Labour Markets, Labour Economics, 6(1), 120.

Nicoletti, G., Bassanini, A., Ernst, E., Jean, S., Santiago, P., Swaim, P. (2001): Product and Labour Markets Interactions in OECD Countries, Economics Department working papers No. 312, December.

Phelps, E. S. (1994): Structural Slumps: The Modern Equilibrium Theory of Unemployment, Interest and Assets, Harvard University Press, Cambridge, MA.

Rowthorn, R. (1995): Capital Formation and Unemployment, Oxford Review of Economic Policy, 11, 26-39.

Rowthorn, R. (1999): Unemployment, Wage Bargaining and Capital-Labour Substitution, Cambridge Journal of Economics, 23, 413-425.

Spector, D. (2004): Competition and the Capital-Labor Conflict, European Economic Review, 48, 25-38.

\section{Appendix A: Derivation of product demand function}

Here we derive the demand function (5) from the basics. Let us start to look at the case of two products $D_{i}, i=1,2$, for which we specify the following CES-utility function

$$
U=\left[2^{-\frac{1}{s}}\left(D_{1}^{\frac{s-1}{s}}+D_{2}^{\frac{s-1}{s}}\right)\right]^{\frac{s}{s-1}},
$$

where $s>1$. Maximizing the utility function (A.1) with respect to $D_{i}$ for $i=1,2$ subject to the budget constraint $M=p_{1} D_{1}+p_{2} D_{2}$ gives the following relationship 
between demand and prices $\left(\frac{p_{1}}{p_{2}}\right)^{-s}=\frac{D_{1}}{D_{2}}$. Using this and the budget constraint yields $M=p_{1}^{1-s} p_{2}^{s} D_{2}+p_{2} D_{2}$ from which we can solve for $D_{2}$, and analogously $D_{1}$. We end up with the following demand functions

$$
D_{1}=\frac{M}{p_{1}+p_{1}^{s} p_{2}^{1-s}} \quad \text { and } \quad D_{2}=\frac{M}{p_{2}+p_{2}^{s} p_{1}^{1-s}}
$$

In order to derive the index of the aggregate price level associated with the utility function (A.1) we proceed as follows. Minimizing the expenditure of getting the utility level $\bar{u}$ w.r.t. $D_{i}$, i.e. $\min C=p_{1} D_{1}+p_{2} D_{2}$ s.t. $U \geq \bar{u}$, yields

$$
p_{i}-\lambda\left[D_{1}^{\frac{s-1}{s}}+D_{2}^{\frac{s-1}{s}}\right]^{\frac{1}{s-1}} D_{i}^{-\frac{1}{s}} 2^{-\frac{1}{s-1}}=0 \text { for } i=1,2
$$

where $\lambda$ is the Lagrangian multiplier associated with the utility constraint $U \geq \bar{u}$. Denoting $D_{1}^{\frac{s-1}{s}}+D_{2}^{\frac{s-1}{s}}=\bar{u}^{\frac{s-1}{s}} 2^{-\frac{1}{s}}$ we can rewrite (A.3) as $p_{i}-\lambda \bar{u}^{\frac{1}{s}} D_{i}^{-\frac{1}{s}} 2^{-\frac{1}{s}}=0$ for $i=1,2$ so that we can solve $D_{i}^{\frac{s-1}{s}}=\lambda^{s-1} p_{i}^{1-s} \bar{u}^{\frac{s-1}{s}} 2^{-\frac{(s-1)}{s}}$ for $i=1,2$. Using this expression we get $D_{1}^{\frac{s-1}{s}}+D_{2}^{\frac{s-1}{s}}=\bar{u}^{\frac{s-1}{s}} 2^{\frac{1}{s}}=\lambda^{s-1}\left[p_{1}^{1-s}+p_{2}^{1-s}\right]^{\frac{s-1}{s}} 2^{-\frac{(s-1)}{s}}$ so that $\lambda^{s-1}=2\left[p_{1}^{1-s}+p_{2}^{1-s}\right]^{-1}$. Substituting this for $\lambda^{s-1}$ in $D_{i}^{\frac{s-1}{s}}=\lambda^{s-1} p_{i}^{1-s} \bar{u}^{\frac{s-1}{s}} 2^{-\frac{(s-1)}{s}}$ gives the compensated demands

$$
D_{i}^{c}=p_{i}^{-s}\left[p_{1}^{1-s}+p_{2}^{1-s}\right]^{\frac{s}{1-s}}\left[\frac{1}{2}\right]^{\frac{1}{s}} \bar{u} \quad \text { for } \quad i=1,2
$$

The expenditure function $C\left(p_{1}, p_{2}, \bar{u}\right)$ in the case of two goods can now be written as

$$
C\left(p_{1}, p_{2}, \bar{u}\right)=p_{1} D_{1}^{c}+p_{2} D_{2}^{c}=P \bar{u}, \text { where } P \equiv\left[\frac{1}{2}\left(p_{1}^{1-s}+p_{2}^{1-s}\right)\right]^{\frac{1}{1-s}}
$$


Finally, using the index of the aggregate price level $P$ in (A.2) we end up with equation (4) in the text in the case of two products. It is straightforward to generalize this for the case of $n$ products. Q.E.D.

\section{Appendix B: Derivation of wage elasticity of labour demand}

By using the production function we can write the wage elasticity of labour demand as follows

$$
\eta(k, s)=-\frac{L_{w} w}{L}=-\frac{p R_{L}}{L\left[p R_{L L}+p_{L} R_{L}\right]}=-\frac{1}{L \frac{R_{L L}}{R_{L}}+L \frac{p_{L}}{P}}
$$

where the specification (1a) of the text implies $k=\frac{K}{L}, \quad R_{L}=X^{\frac{1}{\sigma-1}} a L^{-\frac{1}{\sigma}}$, $X=(1-a) K^{\frac{\sigma-1}{\sigma}}+a L^{\frac{\sigma-1}{\sigma}}$ and $R_{L L}=-\frac{1}{\sigma} a X^{\frac{1}{\sigma-1}} L^{-\frac{1}{\sigma}-1}+\frac{1}{\sigma} X^{\frac{1}{\sigma-1}-1} a^{2} L^{-\frac{2}{\sigma}}$. Moreover, since it holds that $p_{i}=\left[X^{\frac{\sigma}{\sigma-1}} \frac{P^{1-s}}{M}\right]^{-\frac{1}{s}}$ and $\frac{\partial p_{i}}{\partial L_{i}}=-\frac{1}{s} p_{i} X^{-1} a L^{-\frac{1}{\sigma}}$ we get

$$
L \frac{p_{L}}{p}=-\frac{1}{s} X^{-1} a L^{\frac{\sigma-1}{\sigma}}
$$

and

$$
\frac{L R_{L L}}{R_{L}}=\frac{-\frac{1}{\sigma} a X^{\frac{1}{\sigma-1}} L^{-\frac{1}{\sigma}}+\frac{1}{\sigma} X^{\frac{1}{\sigma-1}-1} a^{2} L^{-\frac{2-\sigma}{\sigma}}}{X^{\frac{1}{\sigma-1}} a L^{-\frac{1}{\sigma}}}=\frac{1}{\sigma}\left[X^{-1} a L^{\frac{\sigma-1}{\sigma}}-1\right]
$$

Using (B.2) and (B.3) the wage elasticity of substitution can be written as

$$
\eta(k, s)=\frac{-1}{\frac{1}{\sigma}\left[X^{-1} L^{\frac{\sigma-1}{\sigma}}-1\right]-\frac{1}{s} X^{-1} L^{\frac{\sigma-1}{\sigma}}}=\frac{\sigma\left(1+\frac{1-a}{a} k^{\frac{\sigma-1}{\sigma}}\right)}{\frac{\sigma}{s}+\frac{1-a}{a} k^{\frac{\sigma-1}{\sigma}}}
$$

Q.E.D. 